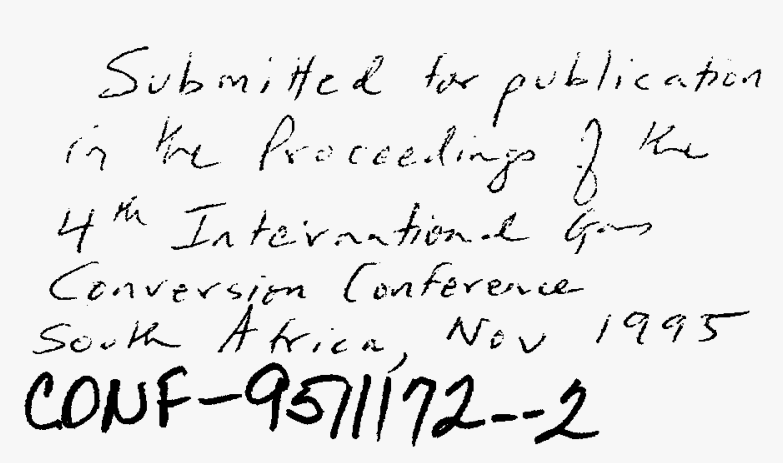

\title{
The Role of Catalyst Activation on the Activity and Attrition of Precipitated Iron Fischer - Tropsch Catalysts
}

\author{
Abhaya K. Datye ${ }^{1}$, Mehul D. Shroff ${ }^{1}$, Mark S. Harrington ${ }^{2}$, Kent E. Coulter ${ }^{2}$, Allen G. Sault ${ }^{2}$ \\ and Nancy B. Jackson ${ }^{2}$ \\ 1 Department of Chemical and Nuclear Engineering and UNM/NSF Center for Micro- \\ Engineered Ceramics, University of New Mexico, Albuquerque, NM 87131. ${ }^{2}$ Sandia \\ National Laboratories, Albuquerque, NM 87185.
}

\section{INTRODUCTION}

The Fischer - Tropsch Synthesis (FTS) is an important step in the manufacture of hydrocarbon fuels from coal. The use of iron - based catalysts is attractive not only due to their low cost and ready availability, but also due to their high water-gas shift activity which makes it possible to use these catalysts with low $\mathrm{H}_{2} / \mathrm{CO}$ ratios. However, these catalysts are fraught with problems, particularly catalyst attrition and deposition of carbon during reaction. Previous work $(1,2)$ has shown that the method of catalyst activation can profoundly affect the reactivity and surface properties of the catalyst. From the standpoint of commercial operation, it would be desirable to activate the catalyst in-situ in the syngas mixture. However, both pre-reduction in $\mathrm{H}_{2}$ and in $\mathrm{CO}$ have been shown to yield active catalysts (2-4). The objective of this study is to investigate the role of these pretreatments on the iron phases present in the catalyst. As we show in this paper, we find that the activation treatment is also directly responsible for catalyst attrition, which occurs at the nanometer scale in these catalysts.

\section{EXPERIMENTAL}

A binderless, precipitated and spray - dried $\mathrm{Fe}_{2} \mathrm{O}_{3}-\mathrm{CuO}-\mathrm{K}_{2} \mathrm{O}$ catalyst with an initial BET surface area of $27 \mathrm{~m}^{2} / \mathrm{g}$ was used in a differential fixed-bed reactor. Four pretreatment methods were studied. The first three pretreatments were for a period of $2 \mathrm{~h}$ either in flowing $\mathrm{CO}$ at $543 \mathrm{~K}$, in syngas $\left(\mathrm{H}_{2} / \mathrm{CO}=0.7\right)$ or in flowing $\mathrm{H}_{2}$ at $543 \mathrm{~K}$. At our space velocity $\left(\approx 4000 \mathrm{~h}^{-1}\right)$ the 2 hour reduction in $\mathrm{H}_{2}$ transformed the catalyst to magnetite, hence we refer to this treatment as mild $\mathrm{H}_{2}$ activation. The fourth pretreatment was a full $\mathrm{H}_{2}$ reduction to $\alpha-\mathrm{Fe}$ at a space velocity of $10,000 \mathrm{~h}^{-1}$ at $543 \mathrm{~K}$ for $75 \mathrm{~h}$. Subsequent reactions were carried out at 523 $\mathrm{K}$ with $\mathrm{H}_{2} / \mathrm{CO}=0.7$. In all studies, approximately $1 \mathrm{~g}$ batches of the catalyst were used. Experimental procedures for reactivity measurement and catalyst characterization are described in detail elsewhere (5).

\section{RESULTS}

The rate of formation of $\mathrm{CH}_{4}$ was used as an indicator of the Fischer - Tropsch activity of the catalyst. The results after each of the three activation treatments are shown in Fig. 1. As can be seen from the figure, $\mathrm{CO}$ activation yielded the most active catalyst. The syngas activated catalyst was less active and the catalyst after mild $\mathrm{H}_{2}$ activation was completely inactive at the start of the reaction. However, over time, both the syngas and the mild $\mathrm{H}_{2}$ 
activated catalysts picked up activity. In contrast, the catalyst reduced to $\alpha$-Fe showed no measurable activity even after 24 hours on stream, and remained inactive even when the reaction temperature was raised to $623 \mathrm{~K}$. We will first explore the reasons for the differing activities of the $\mathrm{CO}$ treated sample and the one reduced in $\mathrm{H}_{2}$ to metallic $\mathrm{Fe}$.

\subsection{Why does severe $\mathrm{H}_{2}$ reduction lead to inactive catalysts?}

Figs. $2 \mathrm{a}$ and $2 \mathrm{~b}$ show sample weight as a function of time for the catalysts pretreated in $\mathrm{CO}$ and after severe $\mathrm{H}_{2}$ reduction. The corresponding Figs. $3 \mathrm{a}$ and $3 \mathrm{~b}$ show the weight change after these activation treatments when the catalyst was exposed to the synthesis gas reaction mixture. It can be inferred from Fig. $2 b$ that $\mathrm{H}_{2}$ reduction converts the catalyst to $\alpha-\mathrm{Fe}$ corresponding to a weight decrease of $30 \%$. On the other hand, the $\mathrm{CO}$ pretreatment causes an $18 \%$ drop in weight followed by a gradual increase in weight. Transformation of $\alpha-\mathrm{Fe}_{2} \mathrm{O}_{3}$ to $\chi-\mathrm{Fe}_{5} \mathrm{C}_{2}$ should have resulted in a weight decrease of $24 \%$. Therefore, this data suggests a transformation to the carbide phase with carbon deposition accounting for the weight gain.

The behavior of the $\mathrm{CO}$ and $\mathrm{H}_{2}$ activated catalysts is dramatically different when exposed to syngas at $523 \mathrm{~K}$. The $\mathrm{CO}$ activated catalyst shows a steady increase in weight with time, again consistent with accumulation of carbon on the surface. In contrast, the $\mathrm{H}_{2}$ activated sample first shows a relatively rapid weight gain which suggests transformation of the metal into carbide, but the subsequent weight gain is negligible in comparison with the CO-activated sample.

Fig. 4 shows the $\mathrm{Fe} 2 p$ XPS spectrum after $\mathrm{CO}$ activation and after $\mathrm{H}_{2}$ activation at $543 \mathrm{~K}$. While the catalyst is reduced to metallic $\mathrm{Fe}$ in $\mathrm{H}_{2}$, the $\mathrm{CO}$ treated sample shows magnetite as the only iron surface phase. This is surprising in view of the TGA results and Xray powder diffraction $(\mathbf{5 , 6}$, which provide clear evidence for transformation into the carbide phase. A straightforward explanation could be that the $\mathrm{CO}$ treated sample contains bulk carbide with magnetite on the surface. We shall show later in this paper that this is not a correct explanation for the inability to observe the carbide by XPS. It is also of interest to examine other surface species that are present on these catalysts after activation. Fig. 5 shows the Auger electron spectra after $\mathrm{CO}$ activation and after $\mathrm{H}_{2}$ activation. The $\mathrm{CO}$ pretreated sample shows a $\mathrm{C}$ peak that is absent on the $\mathrm{H}_{2}$ activated sample which shows instead large amounts of $\mathrm{S}$ and $\mathrm{K}$ on the Fe surface. The increase in surface concentration of $\mathrm{K}$ and $\mathrm{S}$ is consistent with a decrease in the surface area after $\mathrm{H}_{2}$ reduction, and segregation of $\mathrm{S}$ and $\mathrm{K}$ present in the bulk of the catalyst to the surface when the iron oxide is completely reduced to metallic iron. The large $S$ concentration, approaching a monolayer is undoubtedly responsible for the complete Ioss of $\mathrm{F}-\mathrm{T}$ activity on the catalyst subjected to severe $\mathrm{H}_{2}$ reduction.

\subsection{Relationship between carbide formation and catalyst activity}

Our results indicate that the activity for methane formation can be directly related to the extent of carbide formation during the activation stage. We have followed these catalysts through 45 hours of syngas reaction and find that the sequence of phase transformations is similar regardless of the initial activation step. The sequence of transformations is shown in the TEM images Fig. 6a-d for the syngas-activated catalyst. Fig. 6a shows the as-received catalyst which contains single crystals of hematite $\left(\alpha-\mathrm{Fe}_{2} \mathrm{O}_{3}\right)$ located within $\approx 30 \mu \mathrm{m}$ diameter agglomerates. The hematite crystals contain internal voids that give rise to the characteristic "Swiss-cheese" morphology. The first step in the activation process is a rapid transformation form hematite into magnetite. In our flow reactor, this transformation is complete within $2 \mathrm{~h}$ regardless of the activation treatment. At higher space velocities, such as those used in our 

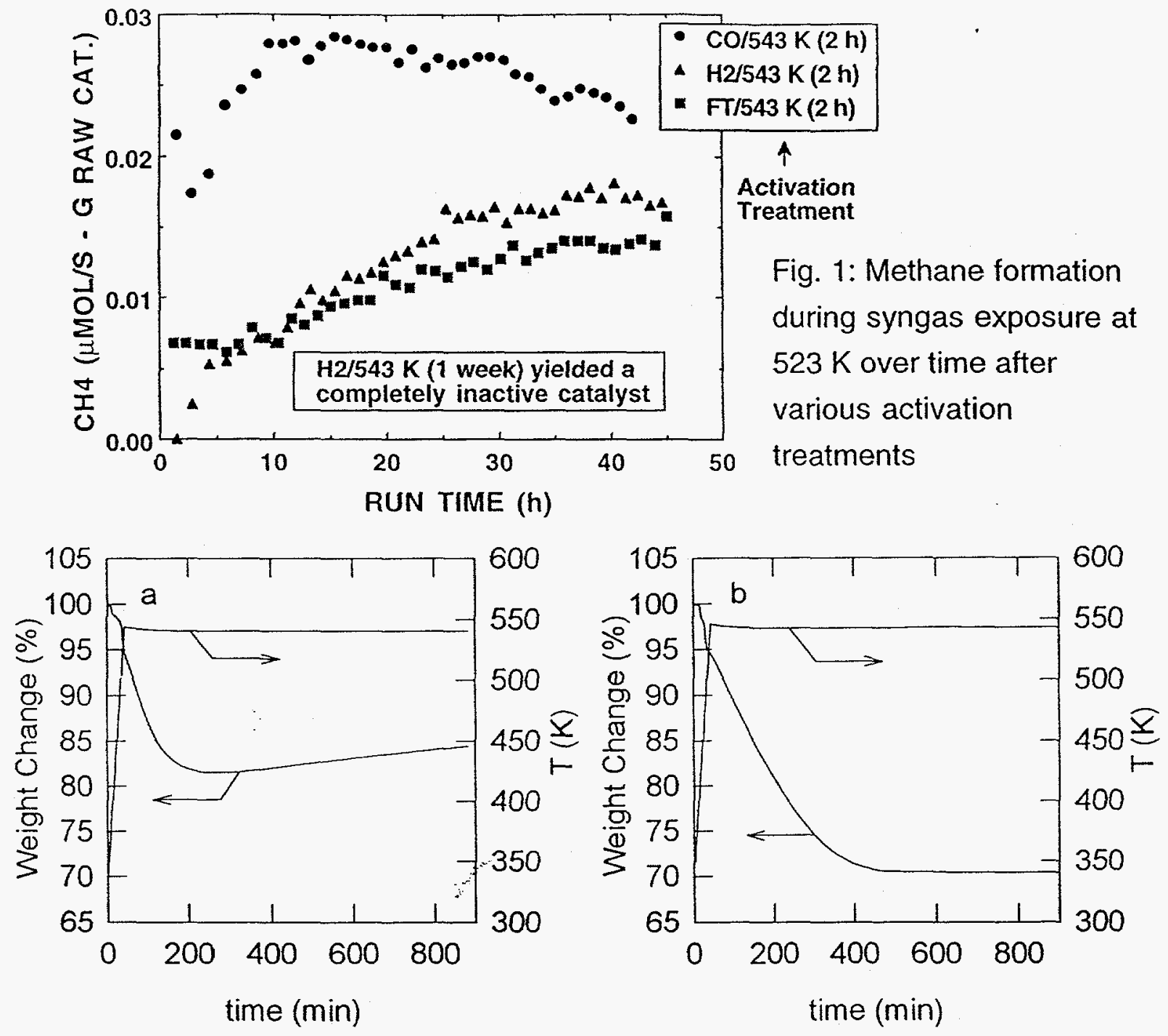

Fig. 2: TGA plots during (a) $\mathrm{CO}$ and (b) severe $\mathrm{H}_{2}$ activation at $543 \mathrm{~K}$.

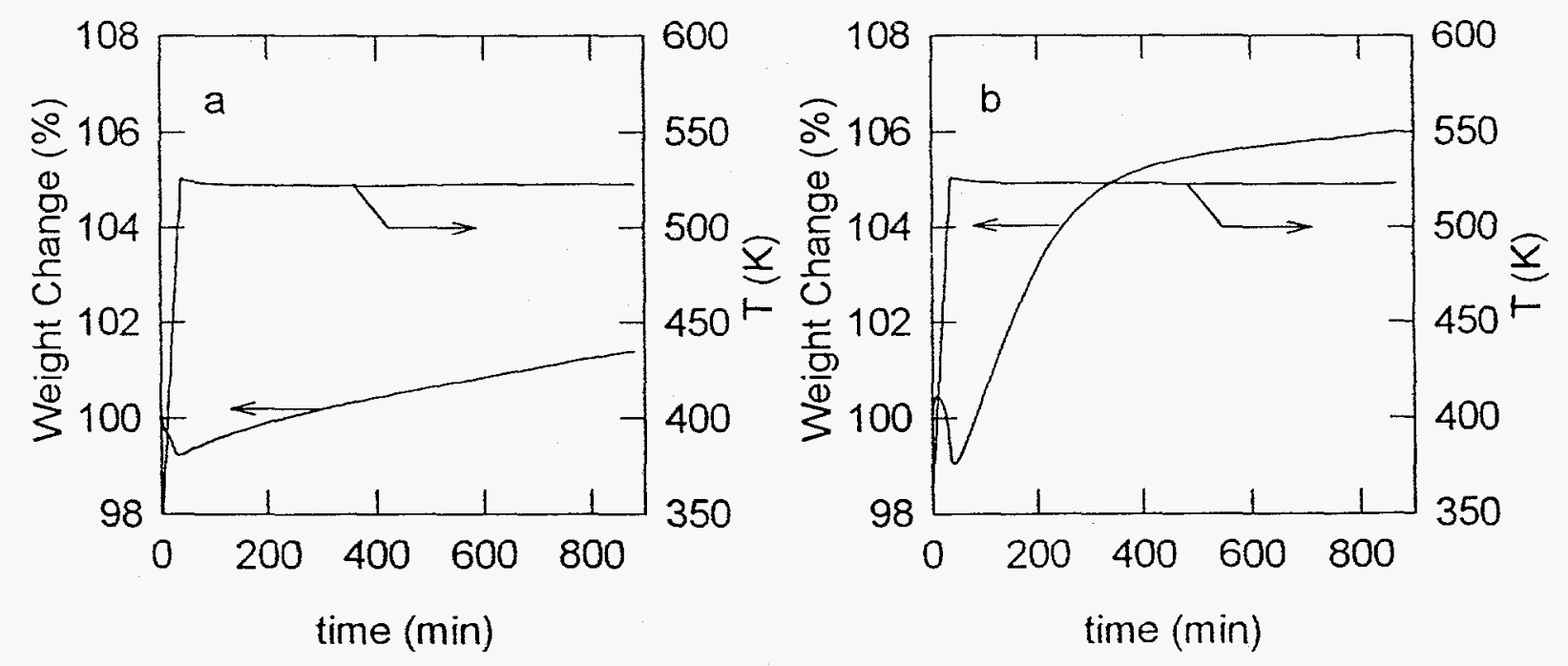

Fig 3: TGA plots during syngas exposure at $523 \mathrm{~K}$ following (a) $\mathrm{CO}$ and (b) severe $\mathrm{H}_{2}$ activation at $543 \mathrm{~K}$. 
TGA runs, the transformation occurs even faster, within a few minutes at $543 \mathrm{~K}$. As shown in Fig. $6 \mathrm{~b}$ this transformation is pseudomorphic and retains the shape and internal morphology of the hematite crystals. The next step involves a slow transformation of the magnetite into the iron carbide. During this step, the crystals of magnetite start to break up while the carbide forms as nodules within the particle. The carbide crystallites are invariably covered with a layer of amorphous carbon as shown in Fig. 6c. Catalyst activation ultimately converts the magnetite almost completely into the carbide crystallites. The change in density going from the magnetite to the carbide and the presence of the surface carbon causes a complete break-up of the parent hematite crystals as seen in Fig. 6d. These figures show that catalyst activation is accompanied by a nano-scale attrition.

In previous work we have shown in detail the morphology of these catalysts under CO and $\mathrm{H}_{2}$ activation. Similar trends were observed with the other activation treatments, but the extents of carbidization differed, as could be seen also from bulk elemental analyses carried out to quantify the carbon content $(\mathbf{5 , 6 )}$. Our results show that mild reduction treatments that do not reduce the catalyst to $\alpha$-Fe are able to activate the catalyst with the activity for methane formation being related to the degree of carbide formation. The carbide particles are always covered with a 2-4 $\mathrm{nm}$ layer of amorphous carbon making the carbide phase difficult to detect by surface analysis probes such as XPS. Indeed, when these catalysts were Ar ion etched, the underlying carbide could be readily seen by XPS. The complex microstructure of this catalyst explains why similar XPS results have been used to infer that the working catalyst may contain

magnetite at the surface with carbide being underneath the magnetite (7). We have also discovered that catalyst passivation is a very important step in the study of microstructure. If the passivation is not performed carefully, the catalyst will transform almost completely to magnetite upon air exposure giving the erroneous conclusion that magnetite is the only phase present on the surface of a working catalyst. We have used a very careful passivation process that involves purging the reactor with $\mathrm{He}$ at the reaction temperature, cooling to room temperature and introducing a dilute $\mathrm{O}_{2}$ stream in $\mathrm{He}$ such that the observed exotherm is no more than $2-3 \mathrm{~K}$. The oxygen concentration is gradually increased to $20 \%$ over 30 min before the sample is withdrawn for analysis. With such passivation, the $\alpha$-Fe phase is covered with a layer of magnetite no greater than 2-3 nm. However, in the case of the carbide, we find that the amorphous carbon layer (under proper passivation) prevents the growth of a surface magnetite layer and hence allows us to image the carbide as seen in Fig. 6c and 6d. Fig. 7 shows a schematic illustration of the microstructural transformations in the catalyst as a result of activation and reaction.

\section{CONCLUSIONS}

The results of this work indicate that magnetite is not catalytically active for FTS in precipitated, unsupported iron catalysts, but the formation of the carbide phase is necessary to obtain FTS activity. The transformation of magnetite to carbide, though essential to obtain FTS activity, also causes the catalyst to break down. This can lead to severe problems during operation in a commercial slurry phase reactor. The results presented here imply that activation and attrition are simultaneous and complementary processes. In another study (8), we show that the catalyst can also undergo attrition on a micron scale which is caused by lack of strength of the forces binding the catalyst primary particles in the agglomerates. Both these processes can make wax separation and product recovery extremely difficult. In this study, we have also shown that $\mathrm{H}_{2}$ reduction of this catalyst to metallic iron is detrimental to subsequent catalyst activity and causes a loss of surface area due to sintering of the iron crystallites. Reduction to metallic Fe also causes impurities such as $S$ to segregate to the surface causing a complete loss of FTS activity. It has been shown that even submonolayer amounts of $S$ can cause a dramatic decrease in FTS activity (9) hence reduction to metallic Fe should be avoided during activation 
of these catalysts. We have shown, however, that a mild $\mathrm{H}_{2}$ reduction to magnetite does not lead to $S$ segregation to the surface, and is therefore acceptable.

\section{REFERENCES}

1. A.G. Sault, J. Catal., 140, 121, (1993).

2. D.B. Bukur, X. Lang, J.A. Rossin, W.H. Zimmerman, M.P. Rosynek, E.B. Yeh and C. Li, Ind. Eng. Chem. Res., 28, 1130, (1989).

3. B. Jager, "Advances in Fischer-Tropsch Catalysis and Processes", CatCon '94, Philadelphia, PA, (1994).

4. C.-S. Huang, L. Xu and B.H. Davis, Fuel Sci. and Technol. International, 11, 639, (1993).

5. M.D. Shroff, D.S. Kalakkad, A.K. Datye, K.E. Coulter, S.D. Köhler, M.S. Harrington, N.B. Jackson and A.G. Sault, J. Catal., in press

6. M.D. Shroff, D.S. Kalakkad, K.E. Coulter, M.S. Harrington, N.B. Jackson, A.G. Sault and A.K. Datye, in "The Chemistry of Transition Metal Carbides and Nitrides", in press.

7. C.S. Kuivila, P.C. Stair and J.B. Butt, J. Catal., 118, 299, (1989).

8. D.S. Kalakkad, M.D. Shroff, S.D. Köhler, N.B. Jackson and A.K. Datye, submitted to Appl. Catal.

9. A.G. Sault and D.W. Goodman, in "Molecule-Surface Interactions", John Wiley \& Sons, New York, (1989), p. 153.

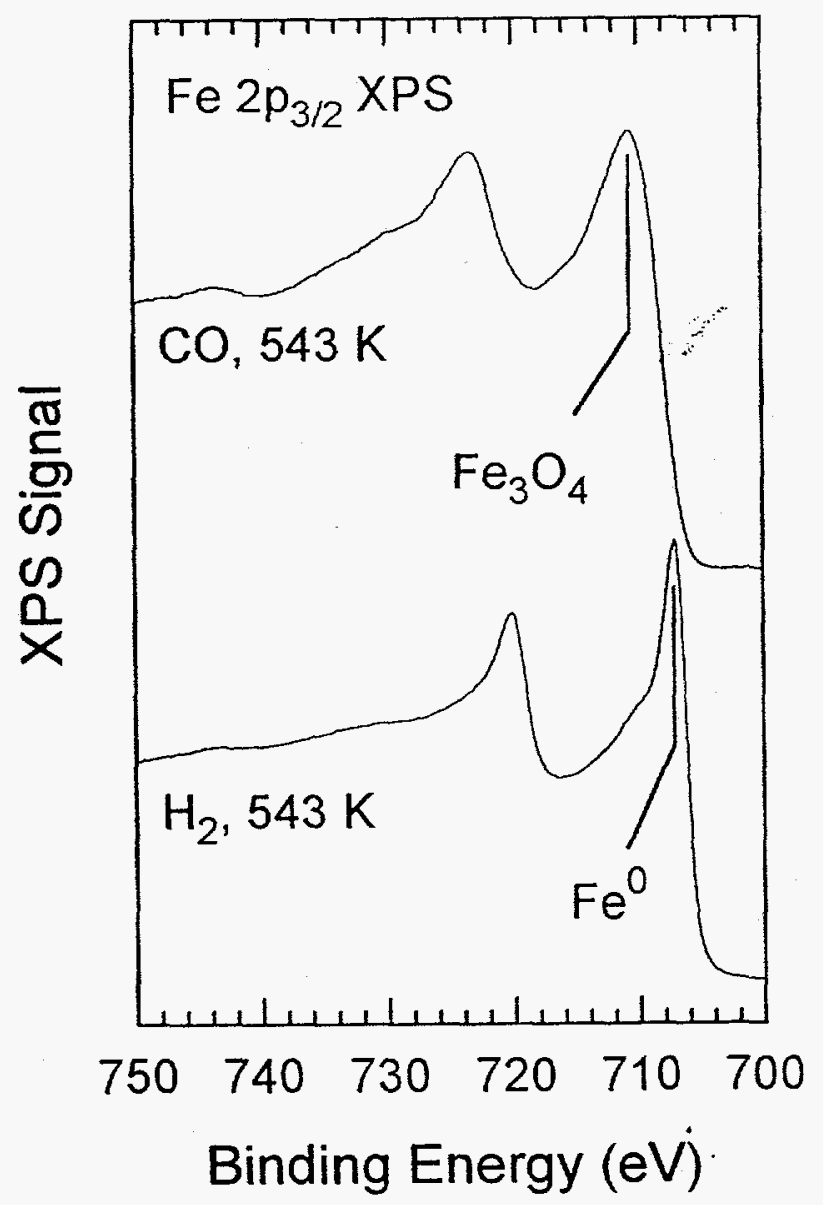

Fig. 4: XPS spectra after $\mathrm{CO}$ and severe

$\mathrm{H}_{2}$ activation at $543 \mathrm{~K}$

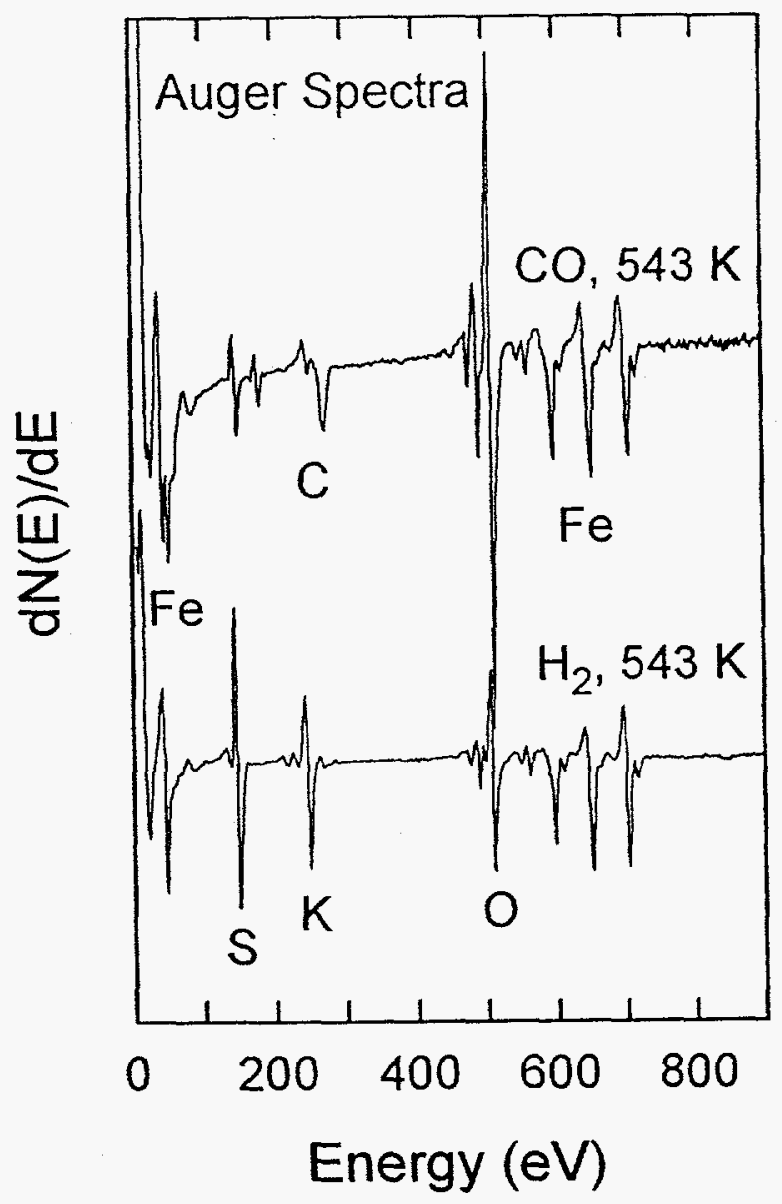

Fig. 5: AES spectra after $\mathrm{CO}$ and severe $\mathrm{H}_{2}$ activation at $543 \mathrm{~K}$ 

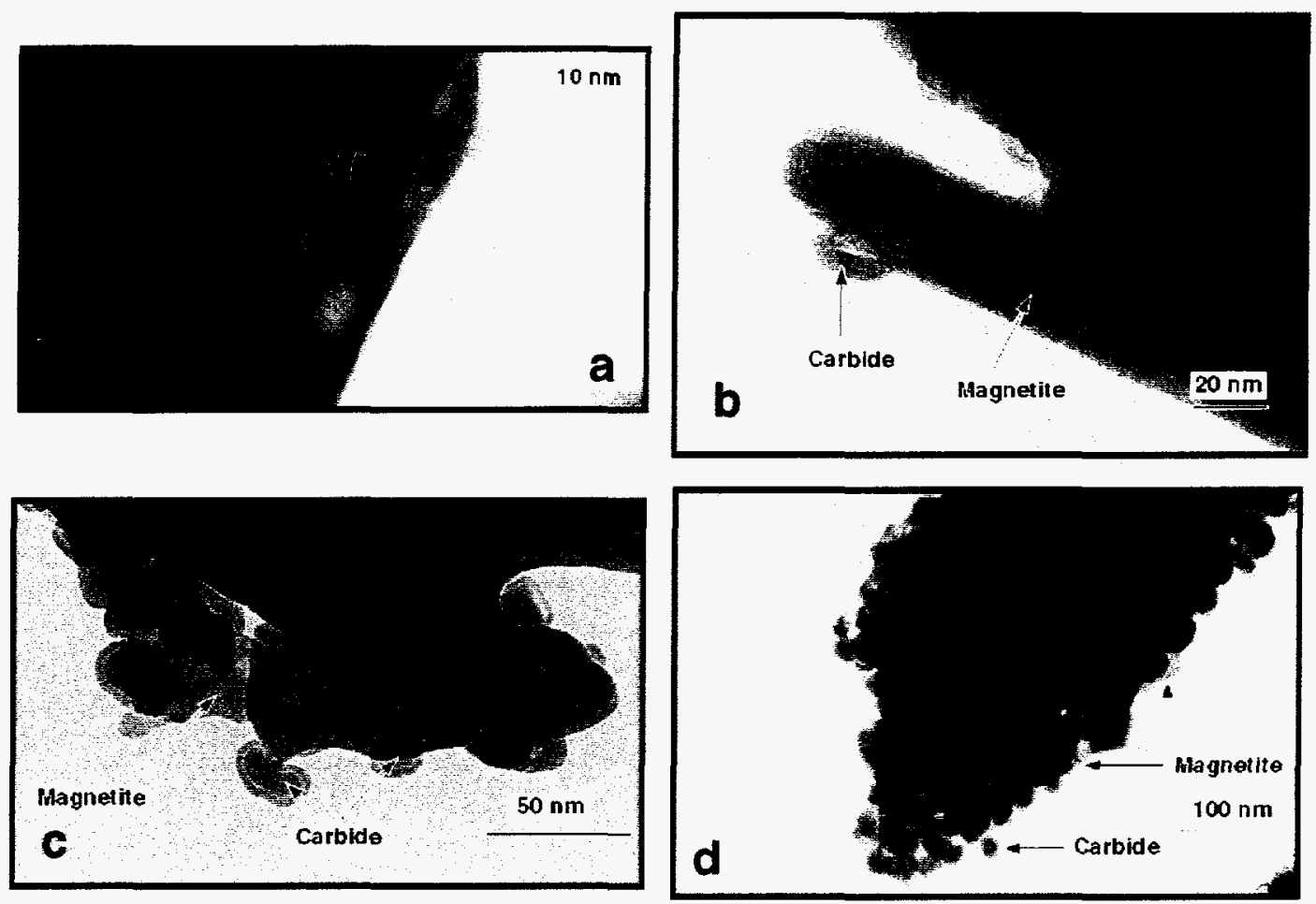

Fig. 6: TEM images of (a) as-received caltalyst and after (b) syngas activation at $543 \mathrm{~K}$ for $2 \mathrm{~h}$ (c) $10 \mathrm{~h}$ FT reaction at $523 \mathrm{~K}$ following syngas activation at $543 \mathrm{~K}$ and (d) $45 \mathrm{~h}$ FT reaction al $523 \mathrm{~K}$ following syngas activation at $5+3 \mathrm{~K}$

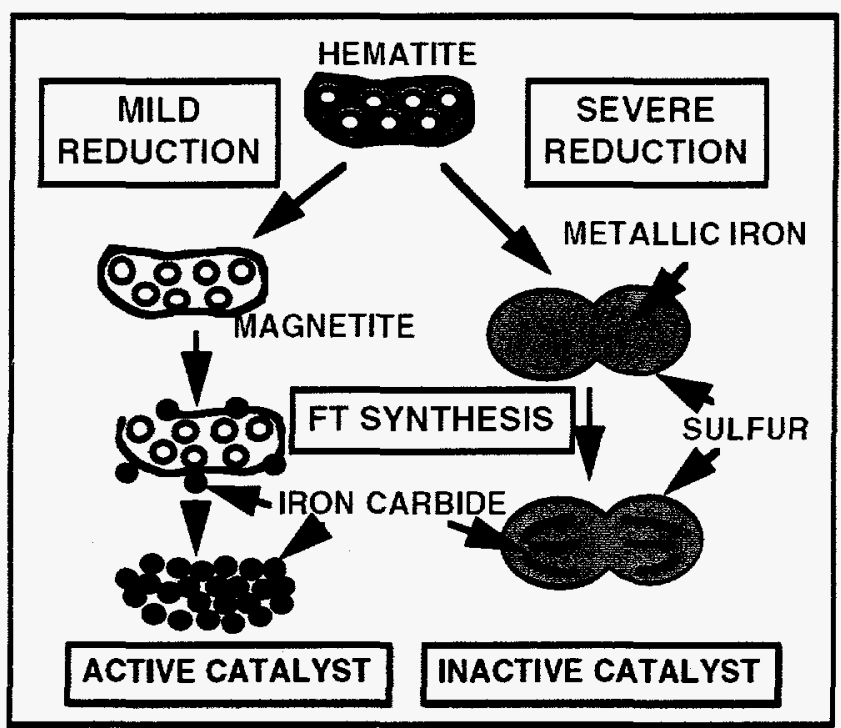

Fig. 7: Schematic illustration of the phase transtionations in the callalyst during atclivation and reactionll 


\section{DISCLAIMER}

This report was prepared as an account of work sponsored by an agency of the United States Government. Neither the United States Government nor any agency thereof, nor any of their employees, makes any warranty, express or implied, or assumes any legal liability or responsibility for the accuracy, completeness, or usefulness of any information, apparatus, product, or process disclosed, or represents that its use would not infringe privately owned rights. Reference herein to any specific commercial product, process, or service by trade name, trademark, manufacturer, or otherwise does not necessarily constitute or imply its endorsement, recommendation, or favoring by the United States Government or any agency thereof. The views and opinions of authors expressed herein do not necessarily state or reflect those of the United States Government or any agency thereof. 